\title{
Nocturnal spikes of growth hormone secretion cause the dawn phenomenon in Type 1 (insulin-dependent) diabetes mellitus by decreasing hepatic (and extrahepatic) sensitivity to insulin in the absence of insulin waning
}

\author{
G.Perriello, P.De Feo, E. Torlone, C.Fanelli, F. Santeusanio, P.Brunetti and G. B. Bolli \\ Istituto di Patologia Speciale Medica e Metodologia Clinica, Università di Perugia, Perugia, Italy
}

\begin{abstract}
Summary. The aim of the present studies was to test the hypothesis that the dawn phenomenon in Type 1 (insulin-dependent) diabetes mellitus is due to a decrease in insulin sensitivity caused by nocturnal spikes of growth hormone. Twelve subjects with Type 1 diabetes were studied on two different occasions, from 24.00 to 02.00 hours, and from 06.00 to 08.00 hours with the euglycaemic clamp technique at two plasma free insulin levels $(\approx 25 \mathrm{mU} / 1, n=7 ; \approx 80 \mathrm{mU} / 1$, $n=5$ ). To eliminate the confounding factor of insulin waning of previous Biostator studies, prior to clamp experiments the diabetic subjects were infused with i.v. insulin by means of a syringe pump according to their minute-to-minute insulin requirements. Insulin sensitivity decreased at dawn as compared to the early night hours $(\approx 30 \%$ increase in the rate of hepatic glucose production, $\approx 25 \%$ decrease in the rate of peripheral glucose utilisation). Plasma insulin clearance did not change overnight. In seven Type 1 diabetic subjects, suppression of nocturnal spikes of growth hormone secretion by
\end{abstract}

somatostatin during basal glucagon and growth hormone replacement resulted in complete abolition of the increased rate of hepatic glucose production at dawn. Replacement of nocturnal spikes of growth hormone faithfully reproduced the increase in hepatic glucose production at dawn of the control study. It is concluded that the dawn phenomenon in Type 1 diabetes mellitus examined during optimal insulin replacement, first, is due solely to a decrease in insulin sensitivity and not to an increase in insulin clearance; second, that the decrease in insulin sensitivity at dawn takes place both in the liver and peripheral tissues; third, that the decrease in hepatic (and most likely extrahepatic) insulin sensitivity at dawn is caused by nocturnal spikes of growth hormone secretion.

Key words: Dawn phenomenon, growth hormone, Type 1 (insulin-dependent) diabetes mellitus, insulin sensitivity, hepatic glucose production, peripheral glucose utilisation.
The dawn phenomenon is an increase in insulin requirement (or in plasma glucose concentration if insulin requirement is not met) which occurs between 04.00 and 08.00 hours in subjects with Type 1 (insulin-dependent) [1-3] and Type 2 (non-insulin-dependent) diabetes mellitus $[4,5]$, in the absence of preceding hypoglycaemia and concomitant hypoinsulinaemia, and in normal nondiabetic subjects as well $[6,7]$. Despite the number of studies published on this subject over the last few years [8], the pathogenesis of the dawn phenomenon is still not completely understood.

Theoretically, the dawn phenomenon might be due to either an increase in insulin clearance [9-12], or to a decrease in insulin sensitivity, or a combination of both factors [8]. Several studies $[3,13,14]$ indicate that insulin clearance does not change overnight. Thus, the dawn phenomenon should be due solely to a decrease in insulin sensitivity [3]. However, in the only study [10] in which nocturnal insulin sensitivity has been examined in subjects with Type 1 diabetes mellitus by means of the euglycaemic-hyperinsulinaemic clamp technique, no dif- ference in insulin action between the early morning and the early night hours has been found.

A second subject of controversy is the identification of the counterregulatory factor(s) which cause(s) the dawn phenomenon in Type 1 diabetes mellitus. Several studies $[11,15-17]$ have proposed that nocturnal surges in growth hormone secretion cause the dawn phenomenon. However, in other studies [18-20] no evidence for a role of growth hormone has been found. Moreover, the interpretation of the studies [11, 15-17] supporting the role of growth hormone in the pathogenesis of the dawn phenomenon, is made difficult by the observation that in those experiments the increase in plasma glucose concentration at dawn was associated with progressive insulin deficiency, either because of loss of biologically active insulin $[11,15]$ during prolonged use of the Biostator [21], or simply because the overnight insulin requirements were underestimated $[16,17]$. The fact that in those studies [11, 15-17] growth hormone was found to play some role, does not necessarily imply that growth hormone contributes to the pathogenesis of the dawn phenomenon, namely a con- 
dition of increased insulin requirements and/or plasma glucose concentration not associated with waning of insulin $[1,3,5-8,19,22]$. Thus, at present, it is not known whether nocturnal spikes of growth hormone secretion play a role in the pathogenesis of the dawn phenomenon in Type 1 diabetes mellitus.

In view of the ongoing controversy on the pathogenesis of the dawn phenomenon in Type 1 diabetes mellitus, the present series of studies were undertaken to test the hypothesis that, firstly, the dawn phenomenon is due to a decrease in insulin sensitivity; and if so, to establish whether the decrease in insulin sensitivity at dawn occurs primarily at the liver or peripheral tissue levels, or if both locations are involved; and, finally, to assess the contribution of the nocturnal surges of growth hormone to the pathogenesis of the dawn phenomenon. To prevent the confounding factor of waning of insulin as a variable, all the experiments of the present studies were run under conditions of overnight optimal insulin replacement by means of a syringe pump [3]. The present studies demonstrate that the dawn phenomenon is due solely to a decrease in insulin sensitivity both at the hepatic and extrahepatic level, not to an increase in insulin clearance; and that such a decrease in insulin sensitivity at dawn is caused by nocturnal spikes of growth hormone secretion.

\section{Subjects and methods}

\section{Subjects}

Informed consent was obtained from 12 subjects with Type 1 diabetes mellitus ( 7 men, 5 women), aged $19-38$ years ( $27 \pm 2$ years, mean $\pm S E M)$, with a duration of diabetes of $5-21$ years $(9 \pm 2$ years), and no residual endogenous insulin secretion as assessed by the plasma C-peptide response to i.v. glucagon [23]. Their $\mathrm{HbA}_{1 \mathrm{c}}$ level was $7.41 \pm 0.52 \%$ [24] (normal range 3.8-6.0\%) and the plasma anti-insulin antibodies at $\mathrm{B}_{\circ}$ was $5.1 \pm 0.7 \%$ [25]. Their body mass index was $22.1 \pm 0.71 \mathrm{~kg} / \mathrm{m}^{2}$. They were on a therapeutic regimen of 3 or 4 daily injections of insulin (regular insulin before breakfast and lunch, and mixture of regular and NPH insulin before supper; or regular insulin before each meal and NPH insulin at bedtime).

\section{Study design}

Three sets of experiments were performed. Seven out of the 12 subjects participated in all the experiments, with the exception of the clamp studies at "high" insulin infusion rate which were carried out on the remaining 5 subjects.

The first set of experiments were performed to assess the difference in insulin sensitivity between the early night and early morning hours by means of a euglycaemic-hyperinsulinaemic clamp study performed between 24.00 and 02.00 hours on one occasion, and between 06.00 and 08.00 hours on a different occasion, approximately one week later. The sequence of these studies was varied at random. The clamp studies were run at "low" $\left(0.3 \mathrm{mU} \cdot \mathrm{kg}^{-1} \cdot \mathrm{min}^{-1}\right.$, in $7 \mathrm{sub}$ jects $)$ and "high" insulin infusion rate $\left(1 \mathrm{mU} \cdot \mathrm{kg}^{-1} \cdot \mathrm{min}^{-1}\right.$, in the remaining 5 subjects). Plasma growth hormone concentration was determined at half hour intervals from 17.00 to 02.00 hours, and from 23.00 to 08.00 hours in the $24.00-02.00$ hours and $06.00-08.00$ hours studies, respectively.

The second and third set of experiments were performed to assess the effects of the nocturnal growth hormone secretion on insulin action in the early morning hours. To mimic the clinical conditions of insulin-treated diabetic subjects, in whom nocturnal plasma insulin concentrations range between 15 and $30 \mathrm{mU} / 1[26,27]$, the clamp experiments were performed at "low" insulin infusion rate $(0.3$ $\mathrm{mU} \cdot \mathrm{kg}^{-1} \cdot \mathrm{min}^{-1}$ ) between 24.00 and 02.00 hours on one occasion, and between 06.00 and 08.00 hours one week later, during either suppression of nocturnal spikes of growth hormone secretion while maintaining its baseline concentration (second set of experiments), or replacement of spikes of growth hormone to mimic the spontaneous nocturnal growth hormone secretion monitored in the first set of experiments (third set of experiments).

In the second set of experiments nocturnal spikes of growth hormone secretion were suppressed by infusion of somatostatin (Stilamin, Serono S.p.A., Rome, Italy, $0.25 \mathrm{mg} / \mathrm{h}$ ), which was initiated $8 \mathrm{~h}$ prior to the clamp studies. To prevent glucagon and absolute growth hormone deficiency, both glucagon (Novo Industri, Bagsvaerd, Denmark) and growth hormone (Crescormon, Kabi Vitrum, Stockholm, Sweden) diluted in $0.9 \% \mathrm{NaCl}$ solution containing $0.5 \%$ human albumin (Immuno S.p. A., Pisa, Italy) were reinfused at the rates of 0.65 and $5 \mathrm{ng} \cdot \mathrm{kg}^{-1} \cdot \mathrm{min}^{-1}$, respectively, as previously reported $[15,28]$.

In the third set of experiments, nocturnal spikes of growth hormone secretion were suppressed by somatostatin, and basal glucagon and growth hormone were replaced as in the second set of experiments, but in addition $i$. v. boluses of growth hormone were given from 21.00 to 02.00 hours in the study $24.00-02.00$ hours, and from 22.00 to 07.30 hours in the study $06.00-08.00$ hours every halfhour in an attempt to reproduce the pattern of nocturnal spikes of spontaneous growth hormone secretion monitored in the first set of experiments, as follows: $25 \mu \mathrm{g}$ from 21.00 through 22.30 hours; $75 \mu \mathrm{g}$ from 23.00 through 24.00 hours; $50 \mu \mathrm{g}$ at 00.30 and 01.00 hours; $75 \mu \mathrm{g}$ from 01.30 through 02.30 hours; $50 \mu \mathrm{g}$ from 03.00 through 04.30 hours; $15 \mu \mathrm{g}$ from 05.00 through 07.30 hours.

\section{Procedures}

Prior to each study, NPH insulin was withdrawn for at least $48 \mathrm{~h}$ in all Type 1 diabetic subjects, and regular insulin was injected before breakfast, lunch, dinner, at bedtime and at 03.00 hours based on capillary blood glucose concentration. All clamp studies were performed after identical periods of fasting $(10 \mathrm{~h})$ and rest in bed $(11 \mathrm{~h})$. On the day on which the clamp studies were performed between 24.00 and 02.00 hours, the last s.c. insulin injection was given at breakfast; between $01.00-01.30$ hours the subjects were placed in bed, and a 18-gauge catheter needle was inserted into a superficial forearm vein for infusion of insulin (Actrapid HM, Novo Industri, diluted to a final concentration of $0.5 \mathrm{U} / \mathrm{ml}$ in $0.9 \% \mathrm{NaCl}$ solution containing $0.5 \%$ human albumin), and glucose ( $20 \%$ solution) by means of separate Harvard pumps (Harvard Apparatus, South Natick, Mass, USA). A 21 -gauge butterfly needle was inserted retrogradely into a dorsal vein of the contralateral hand which was kept warm in a thermoregulated plexiglass box at $65^{\circ} \mathrm{C}$ in order to ensure arterialisation of venous blood [29]. This line was kept patent by an infusion of $0.9 \% \mathrm{NaCl}$ solution $(0.5 \mathrm{ml} / \mathrm{min})$, and was used for intermittent blood sampling. Between $01.30-02.00$ hours the subjects consumed a standard meal ( $725 \mathrm{kcal}, 45 \%$ carbohydrate, $30 \%$ fat, $25 \%$ protein) and insulin was infused at variable rates to prevent plasma glucose concentrations greater than $10 \mathrm{mmol} / \mathrm{l}$ for the first 2 $h$ after the meal. Thereafter, between 16.00 and 24.00 hours, plasma glucose concentration was maintained between 4.5 and $5.5 \mathrm{mmol} / \mathrm{l}$, according to the previously described algorithm [3]. At 21.00 hours a primed $(20 \mu \mathrm{Ci})$ continuous $(0.20 \mu \mathrm{Ci} / \mathrm{min})$ infusion of the $3-{ }^{3} \mathrm{H}$-glucose (New England Nuclear, Boston, Mass, USA) was initiated for determination of glucose turnover. On the day on which the clamp studies were performed between 06.00 and 08.00 hours, the last s. c. insulin injection was given at lunch. Between 19.00-19.30 hours the subjects were placed in bed, the i. v. lines started, the standard meal consumed between 19.30 and 08.00 hours, and insulin infused in a feedback mode to maintain euglycaemia, as described above. No snack was administered after dinner. In these experiments $3-{ }^{3} \mathrm{H}$ - 

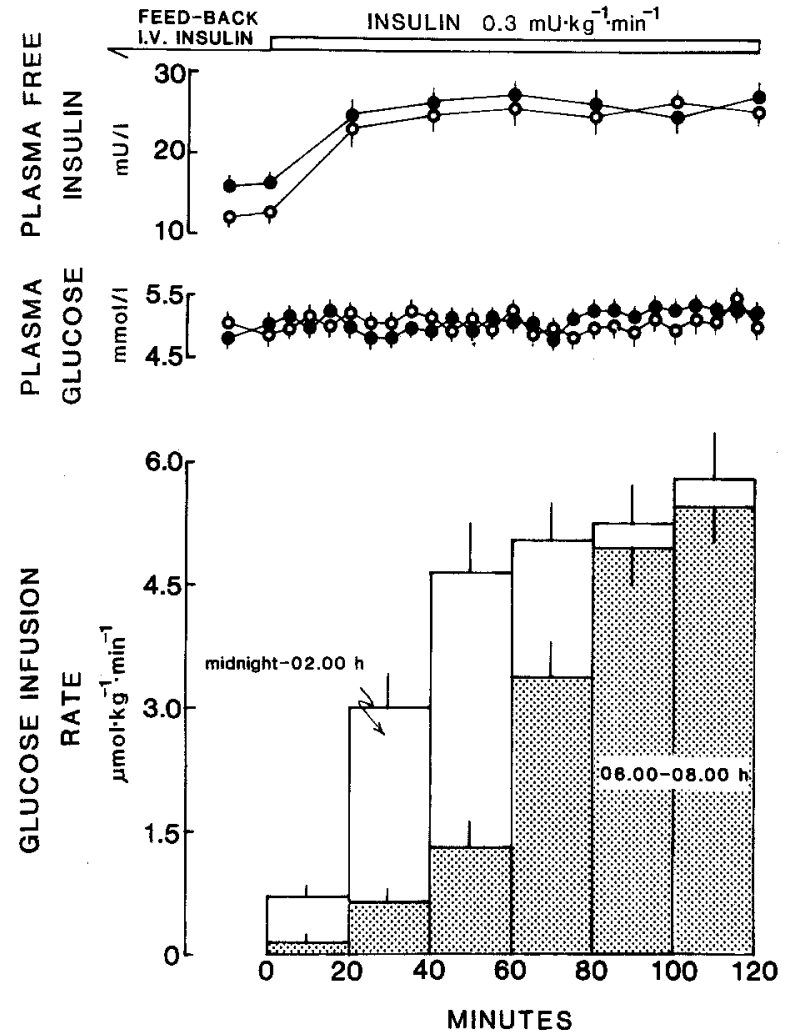

Fig. 1. Glucose infusion rates during a $2 \mathrm{~h}$ euglycaemic clamp at the insulin infusion rate of $0.3 \mathrm{mU} \cdot \mathrm{kg}^{-1} \cdot \mathrm{min}^{-1}$ in seven subjects with Type 1 (insulin-dependent) diabetes mellitus. The subjects were studied on two separate nights, from midnight to $02.00 \mathrm{~h}$ on one accasion, from 06.00 to $08.00 \mathrm{~h}$ on the other occasion. $0-0$ midnight -02.00 hours. $\longrightarrow 06.00$ hours -08.00 hours

glucose infusion was initiated at 03.00 hours. The subjects were able to sleep between 24.00 and 08.00 hours during all the experiments.

\section{Analysis}

Plasma glucose was measured by the glucose oxidase method (Beckman Glucose Analyzer, Beckman Instruments, Fullerton, Calif., USA). Plasma glucose specific activity [30], C-peptide [31], glucagon [32], growth hormone [33] were measured by previously described methods. Plasma free insulin was determined according to the method of Kuzuya et al. [34]. Polyethylene glycol precipitation of plasma insulin antibodies was performed soon after drawing blood samples, as previously described [35]. Rates of glucose production and utilisation were calculated by means of the non-steady-state equations of De Bodo et al. [36], and were "smoothed" according to the method of Miles et al. [37]. As during the euglycaemic-hyperinsulinaemic clamp experiments at the insulin infusion rate of $1 \mathrm{mU} \cdot \mathrm{kg}^{-1} \cdot \mathrm{min}^{-1}$, the calculated rate of hepatic glucose production yielded negative numbers [38], it was assumed that hepatic glucose production was fully suppressed [39] and that therefore the rate of exogenous "cold" glucose infusion equalled the rate of whole body glucose utilisation. Thus, in the clamp studies at "high" insulin infusion rate, the rate of "cold" glucose infusion and not the isotopically calculated glucose turnover, was considered as the real rate of peripheral glucose utilisation. Plasma insulin clearance was calculated as the ratio between insulin infusion and the mean of plasma free insulin concentration at steady-state during the second $h$ of the clamp studies [3].
Statistical analysis

Data in text and figures are given as mean \pm SEM and were evaluated by analysis of variance corrected for repeated measures, leastsquares linear regression, and when appropriate two-tailed, paired $t$-test [40].

\section{Results}

Assessment of insulin action in the early night and the early morning hours (study 1)

Clamp studies at "low" insulin infusion rate $(0.3 \mathrm{mU}$. $\left.\mathrm{kg}^{-1} \cdot \mathrm{min}^{-1}\right)$. Prior to the clamp studies, the insulin infusion rate required to maintain euglycaemia was greater at 06.00 hours compared to that at 24.00 hours $(0.18 \pm 0.02 \mathrm{vs}$ $\left.0.11 \pm 0.01 \mathrm{mU} \cdot \mathrm{kg}^{-1} \cdot \mathrm{min}^{-1}, p<0.05\right)$. During the clamp studies, plasma free insulin concentration was comparable in the study periods $24.00-02.00$ hours and 06.00 08.00 hours $(24.6 \pm 2.2$ vs $25.6 \pm 2.4 \mathrm{mU} / 1$, respectively, $p=\mathrm{NS}$ ) and plasma insulin clearance was no different $\left(12.2 \pm 0.13\right.$ and $11.7 \pm 0.14 \mathrm{ml} \cdot \mathrm{kg}^{-1} \cdot \mathrm{min}^{-1}$, respectively, $p=\mathrm{NS}$ ). Plasma glucose concentrations at baseline and during the clamp studies were comparable, with a coefficient of variation (c.v.) of $4.1 \pm 0.3 \%$. The mean glucose infusion rate required to maintain euglycaemia during the clamp studies was lower in the period $06.00-08.00$ hours compared to the period $24.00-02.00$ hours $(2.65 \pm 0.44$ vs $\left.4.09 \pm 0.68 \mu \mathrm{mol} \cdot \mathrm{kg}^{-1} \cdot \mathrm{min}^{-1}, p<0.05\right)$. However, if the time course of insulin action during the $2 \mathrm{~h}$ clamp was analysed by comparing time intervals of $20 \mathrm{~min}$ each in the two studies, the glucose infusion rate was different only over the initial $80 \mathrm{~min}$ of the two study periods (Fig.1). Prior to the clamp studies, glucose turnover rates at 24.00 hours and at 06.00 hours were no different. Overall the $2 \mathrm{~h}$ clamp study, the rate of hepatic glucose production was greater in the period $06.00-08.00$ hours as compared to the period $24.00-02.00$ hours $(8.46 \pm 0.10$ vs $6.50 \pm 0.72$ $\mu \mathrm{mol} \cdot \mathrm{kg}^{-1} \cdot \mathrm{min}^{-1}, p<0.05$ ) (Fig. 2). However, the differences in hepatic glucose production were evident only over the initial $80 \mathrm{~min}$ of the clamp studies and followed exactly the time course of the rates of cold glucose infusion in Figure 1. The rate of peripheral glucose utilisation was no different (Fig. 2).

Clamp studies at "high" insulin infusion rate (1 $m U$. $\left.\mathrm{kg}^{-1} \cdot \mathrm{min}^{-1}\right)$. Prior to the clamp studies, the insulin infusion rate required to maintain euglycaemia was greater at 06.00 hours compared to that at 24.00 hours $(0.17 \pm 0.03 \mathrm{vs}$ $\left.0.13 \pm 0.01 \mathrm{mU} \cdot \mathrm{kg}^{-1} \cdot \mathrm{min}^{-1}, p<0.05\right)$. During the clamp studies, plasma free insulin concentration was comparable in the periods $24.00-02.00$ hours and $06.00-08.00$ hours ( $79.5 \pm 7$ vs $77 \pm 8 \mathrm{mU} / 1$, respectively, $p=\mathrm{NS}$ ) and plasma insulin clearance in the periods $24.00-02.00$ hours and $06.00-08.00$ hours was no different $(12.6 \pm 0.15$ and $12.9 \pm 0.16 \mathrm{ml} \cdot \mathrm{kg}^{-1} \cdot \mathrm{min}^{-1}$ ). Plasma glucose concentration at baseline and during the clamp studies were comparable (c.v. $4.5 \pm 0.4 \%$ ). The mean glucose infusion rate required to maintain euglycaemia during the clamp studies was lower in the period 06.00-08.00 hours compared to the 

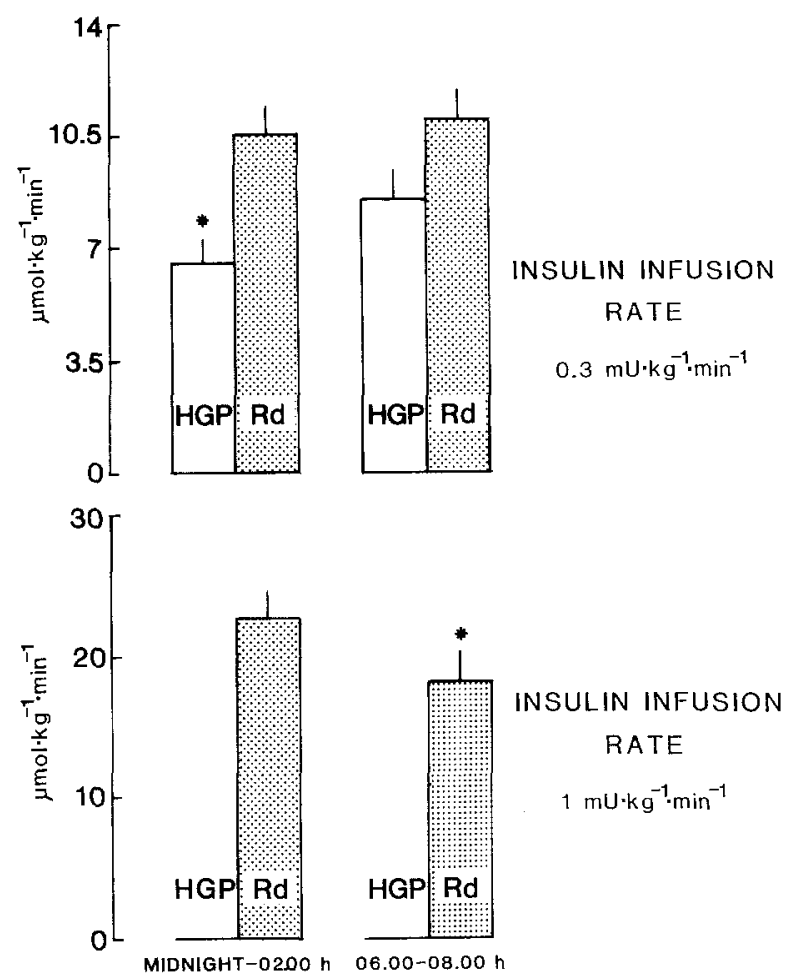

Fig. 2. Rates of hepatic glucose production (HGP) and peripheral glucose utilization (Rd) calculated as mean values over the $2 \mathrm{~h}$ euglycaemic-hyperinsulinaemic clamp studies run between midnight and 02.00 hours (left side) and 06.00 and 08.00 hours (right side), at the insulin infusion rate of $0.3 \mathrm{mU} \cdot \mathrm{kg}^{-1} \cdot \mathrm{min}^{-1}$ (upper panel, $n=7$ Type 1 (insulin-dependent) diabetic subjects) and $1 \mathrm{mU}$. $\mathrm{kg}^{-1} \cdot \mathrm{min}^{-1}$ (lower panel, $n=5$ Type 1 diabetic subjects). HGP is represented as "Zero" in the clamp studies at $1 \mathrm{mU} \cdot \mathrm{kg}^{-1} \cdot \mathrm{min}^{-1}$, but negative numbers were actually obtained. Mean \pm SEM, * $p<0.05$

period $24.00-02.00$ hours $(18.4 \pm 2.75$ vs $23.0 \pm 3.69 \mu \mathrm{mol}$. $\left.\mathrm{kg}^{-1} \cdot \min ^{-1}, p<0.05\right)$. However, as already observed in the clamp studies at low insulin infusion rate, when the time course of insulin action was analysed at 20 min intervals, the glucose infusion rate was different only over the initial 80 min of the two study periods (Fig. 3). Prior to the clamp studies, glucose turnover rates at 24.00 and 06.00 hours were no different. During the clamp studies, hepatic glucose production was assumed to be zero (negative numbers were obtained) both in the periods $24.00-02.00$ hours and $06.00-08.00$ hours. In these studies it was assumed that the rate of "cold" glucose infusion represented the rate of peripheral glucose utilisation (Fig.2).

Correlation between nocturnal plasma growth hormone concentration and insulin action at dawn. When the data from all experiments run between 24.00 and 02.00 hours and from 06.00 to 08.00 hours were analysed, a significant correlation was found between the increased rate of hepatic glucose production at dawn and overnight peak plasma growth hormone levels in the seven Type 1 diabetic subjects studied at "low" insulin infusion rate $(r=0.61$, $p<0.01$ ), and between the reduced rate of glucose utilisation at dawn and overnight peak plasma growth hormone levels in the five subjects studied at "high" insulin infusion rate $(r=0.57, p<0.0 .01)$.
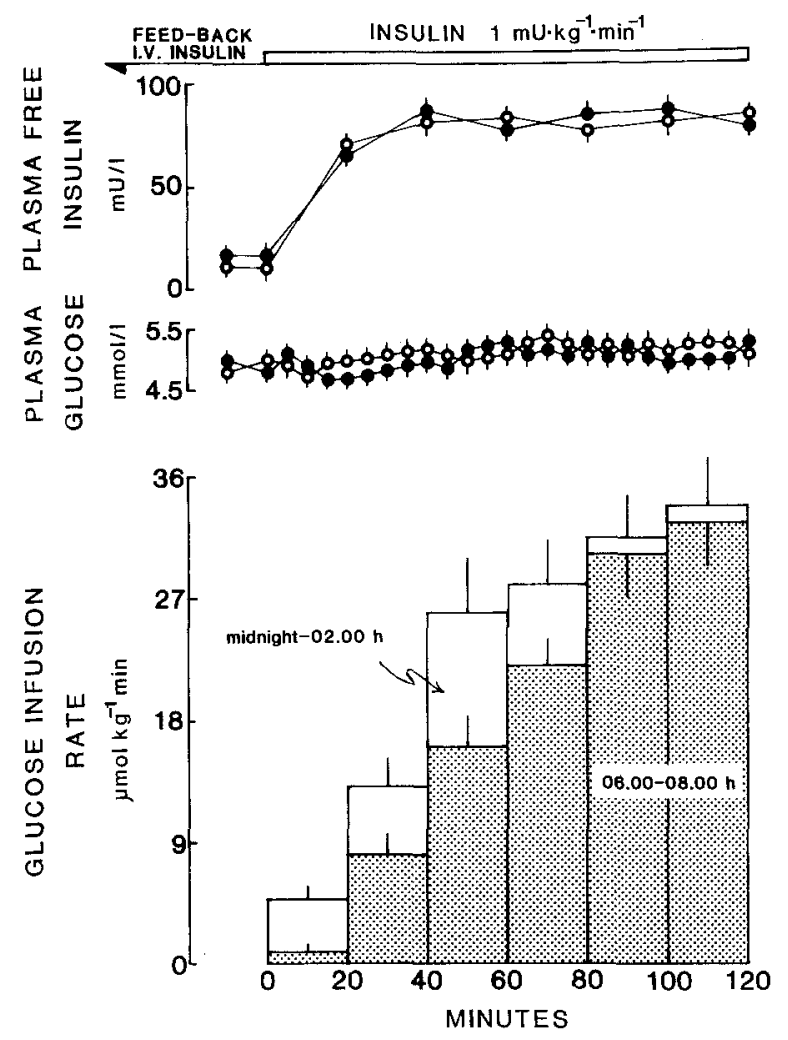

Fig.3. Glucose infusion rates during a $2 \mathrm{~h}$ euglycaemic clamp at the insulin infusion rate of $1 \mathrm{mU} \cdot \mathrm{kg}^{-1} \cdot \mathrm{min}^{-1}$ in five subjects with Type 1 (insulin-dependent) diabetes mellitus. The subjects were studied on two separate nights, from midnight to 02.00 hours on one occasion and from 06.00 to 08.00 hours on the other occasion. $0-0$ midnight 02.00 hours. $\longrightarrow 06.00$ hours -08.00 hours

\section{Effects of suppression and replacement of nocturnal spikes of growth hormone on insulin action in the early night and early morning hours (studies 2 and 3)}

Plasma glucagon concentrations. In the studies 2 and 3 in which somatostatin was infused for 8 h prior to each clamp period and glucagon was reinfused at the rate of 0.65 $\mathrm{ng} \cdot \mathrm{kg}^{-1} \cdot \mathrm{min}^{-1}$ along with growth hormone, plasma glucagon concentrations were similar in study 2 (122 \pm 11 $\mathrm{pg} / \mathrm{ml})$ and study $3(127 \pm 9 \mathrm{pg} / \mathrm{ml})$, and no different from plasma glucagon concentration of study $1(131 \pm 12$ $\mathrm{pg} / \mathrm{ml})(p=\mathrm{NS})$, as previously reported $[15,25]$.

Plasma growth hormone concentrations. In the experiments of study 2 , in which growth hormone secretion was inhibited by somatostatin, but baseline plasma growth hormone concentration was maintained by growth hormone infusion at the rate of $5 \mathrm{ng} \cdot \mathrm{kg}^{-1} \cdot \mathrm{min}^{-1}$, the nocturnal peaks of growth hormone were suppressed. However, baseline plasma growth hormone concentration between 17.00 and 22.30 hours and between 05.00 and 08.00 hours were no different as compared to those of study 1 (Fig.4). In the experiments of study 3 in which intermittent pulses of growth hormone were given between 21.00 and 7.30 hours to mimic the nocturnal peaks of the spontaneous secretion of growth hormone of study 1, plasma growth hor- 


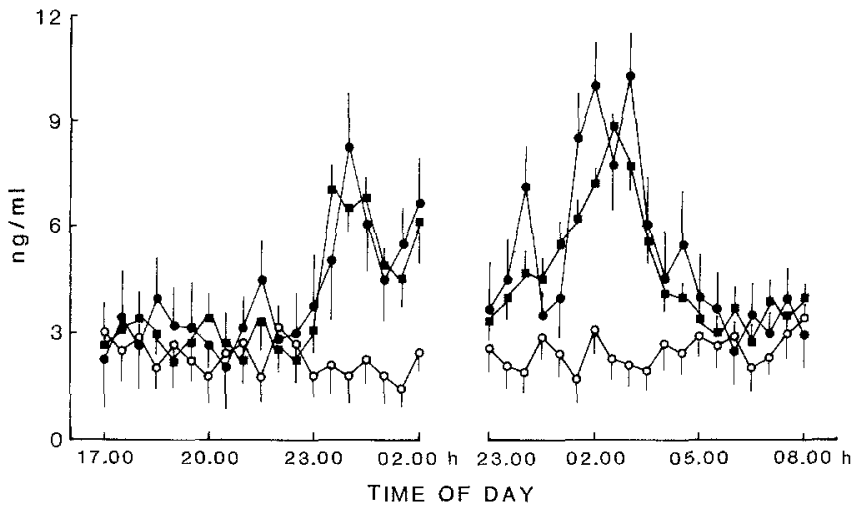

Fig. 4. Plasma growth hormone concentrations before and during the clamp studies run between midnight and 02.00 hours (left panel) and between 06.00 and 08.00 hours (right panel) during spontaneous growth hormone secretion (-) , suppression of nocturnal spikes of growth hormone by somatostatin and reinfusion of basal growth hormone at the rate of $5 \mathrm{ng} \cdot \mathrm{kg}^{-1} \cdot \mathrm{min}^{-1}\left(\mathrm{O}_{-0}\right)$, and after replacement of nocturnal spikes of growth hormone by intermittent boluses (a)

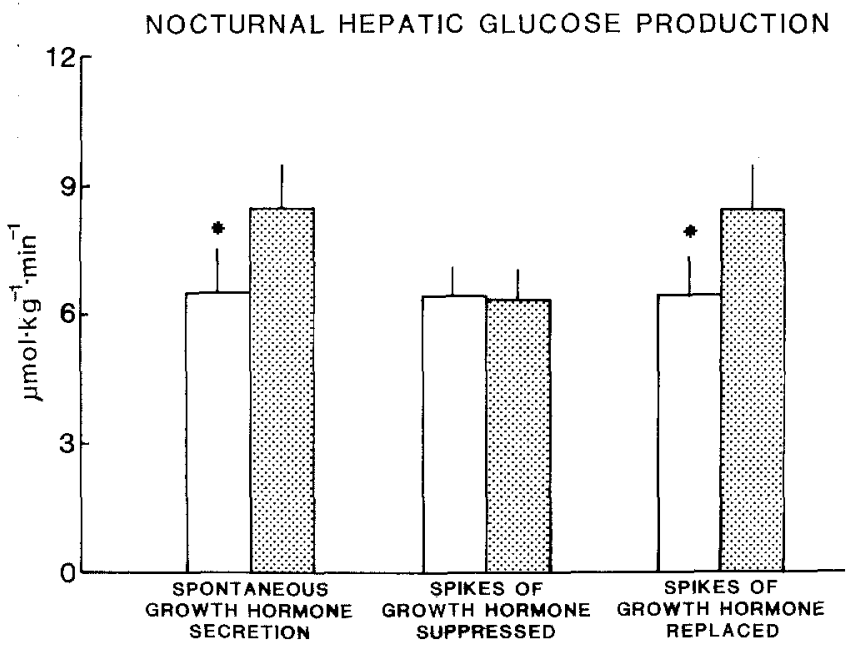

Fig.5. Rates of hepatic glucose production calculated as mean values over the midnight -02.00 hours, and $06.00-08.00$ hours periods in the studies in which nocturnal spikes of growth hormone secretion was either allowed to occur (left side), or suppressed (middle), or reproduced by intermittent pulses of growth hormone (right). Insulin was infused during the $2 \mathrm{~h}$ study period at $0.3 \mathrm{mU}$. $\mathrm{kg}^{-1} \cdot \mathrm{min}^{-1}$. $\square$ midnight -02.00 hours. 06.00 hours -08.00 hours. $n=7$ mean $\pm \widehat{\mathrm{SEM}}, * p<0.05$

mone concentration did not differ at each time point from that of study 1 (Fig. 4).

Nocturnal insulin requirements, plasma free insulin concentrations and insulin clearance. In the experiments in which growth hormone secretion was inhibited by somatostatin and growth hormone replaced to merely maintain its baseline plasma concentration (study 2), the insulin infusion rate required to maintain euglycaemia prior to the clamp studies at 06.00 hours $\left(0.13 \pm 0.02 \mathrm{mU} \cdot \mathrm{kg}^{-1} \cdot \mathrm{min}^{-1}\right)$ was no different from that at 24.00 hours $(0.12 \pm$ $\left.0.02 \mathrm{mU} \cdot \mathrm{kg}^{-1} \cdot \mathrm{min}^{-1}\right)$. However, in the experiments in which intermittent pulses of growth hormone were replaced (study 3 ), the insulin infusion rate required to main- tain euglycaemia prior to the clamp studies at 06.00 hours was greater as compared to that at 24.00 hours $(0.17 \pm 0.03$ vs $\left.0.11 \pm 0.02 \mathrm{mU} \cdot \mathrm{kg}^{-1} \cdot \mathrm{min}^{-1}, p<0.05\right)$. Plasma free insulin concentration in the $24.00-02.00$ and $06.00-08.00$ hours periods of study $2(25.1 \pm 1.9$ vs $26.2 \pm 2.1 \mathrm{mU} / \mathrm{l})$ were no different, neither were these values different from those of study $3(26.0 \pm 2.3 \mathrm{vs} 25.4 \pm 2.2 \mathrm{mU} / \mathrm{l})$ and study 1 $(p=$ NS). Plasma insulin clearance in study $2(11.9 \pm 0.12$ and $11.5 \pm 0.17 \mathrm{ml} \cdot \mathrm{kg}^{-1} \cdot \mathrm{min}^{-1}$, study periods $24.00-02.00$ hours and $06.00-08.00$ hours, respectively) and in study 3 $\left(11.5 \pm 0.14\right.$ and $\left.11.8 \pm 0.13 \mathrm{ml} \cdot \mathrm{kg}^{-1} \cdot \mathrm{min}^{-1}\right)$ were no different as compared to those of study 1 .

Insulin action. Prior to the experiments of study 2 in which the nocturnal spikes of growth hormone secretion were suppressed, but baseline plasma growth hormone replaced, the rates of glucose production and utilisation were no different from those of study 1 in which nocturnal spontaneous secretion of growth hormone was simply monitored (data not shown). In the experiments of study 2 (nocturnal spikes of growth hormone suppressed), the rate of hepatic glucose production in the study period $06.00-08.00$ hours $\left(6.41 \pm 0.67 \mu \mathrm{mol} \cdot \mathrm{kg}^{-1} \cdot \mathrm{min}^{-1}\right)$, was no longer different from that of the study period $24.00-02.00$ hours $\left(6.44 \pm 0.72 \mu \mathrm{mol} \cdot \mathrm{kg}^{-1} \cdot \mathrm{min}^{-1}, p=\mathrm{NS}\right)$. When nocturnal spikes of growth hormone secretion were reproduced in study 3 , the rate of hepatic glucose production in the study period $06.00-08.00$ hours was greater than that of the study period $24.00-02.00$ hours $(8.40 \pm 0.89$ vs $6.47 \pm 0.79 \mu \mathrm{mol} \cdot \mathrm{kg}^{-1} \cdot \mathrm{min}^{-1}$, respectively, $p<0.05$ ), as observed in study 1 in which nocturnal spontaneous secretion of growth hormone was allowed to occur (Fig. 5). However, the differences in hepatic glucose production were evident only over the initial $80 \mathrm{~min}$ of the clamp studies and followed exactly the time course of the rates of cold glucose infusion in Figure 1. Glucose utilisation did not increase in the clamp experiments of study 2 or in those of study 3 (data not shown).

\section{Discussion}

The present studies demonstrate that the dawn phenomenon in Type 1 diabetes mellitus is due to a decrease in insulin sensitivity, rather than to change in insulin clearance, which occurs after 02.00 hours; that such a decrease in insulin sensitivity takes place in the liver and in the peripheral insulin-dependent tissues as well; finally, that nocturnal spikes of secretion of growth hormone are responsible for most, if not all, of the decreased insulin sensitivity which causes the dawn phenomenon. Notably, the results of the present studies were obtained during optimal insulin replacement overnight, which prevented the confoundingeffects of waning of insulin of previous studies [11,15-17] that can itself cause hyperglycaemia in the early morning hours not specifically due to the dawn phenomenon [8].

The pattern of the decreased insulin sensitivity observed at dawn in the present clamp experiments deserves comment. When the glucose infusion rates required to maintain euglycaemia in the clamp studies were analysed at time intervals of $20 \mathrm{~min}$ each, the impairment in insulin 
action at dawn as compared to the night hours was evident primarily over the initial $80 \mathrm{~min}$ of the clamp studies, but not during the last 40 min of the studies (Fig. 1 and 3). Such an observation is compatible either with a progressive increase in insulin sensitivity after 01.30 hours, or with a progressive increase in insulin sensitivity after 07.30 hours or with a combination of these two factors. The former hypothesis speaks in favour of an early onset of the dawn phenomenon during the night hours, whereas the latter suggests that the dawn phenomenon is fully reversed by 07.30 hours. The design of the present experiments does not allow one to conclude which one of the two above hypothesis is correct. Regardless of the explanation, however, the present study suggests that the temporal duration of the dawn phenomenon is quite short, and that it causes more of a delay in onset of insulin action, transient in nature, rather than a persistent condition of impaired insulin action. Previous studies in which insulin has been infused at a fixed rate $[9,13,19,22]$ or in a feed-back mode [3] have provided evidence for a rise in plasma glucose concentration between 04.30 and 05.00 hours. Thus, it is likely that the period of decreased insulin sensitivity at dawn is located approximately between 05.00 and 07.00 hours.

In the present experiments, insulin sensitivity at dawn was reduced by $\approx 30 \%$ as compared to the early night hours. Although such a difference in insulin sensitivity might appear quite modest, it should be considered that the present experiments were made after identical periods of fasting $(10 \mathrm{~h})$ prior to each study. In the real life of Type 1 diabetic subjects, the difference in insulin action between dawn and early night hours might be considerably greater than that found in the present studies. In fact, the carry-over effect of regular insulin given with the evening meal might exaggerate insulin sensitivity in the early night hours (Staub-Traugott effect) [41], whereas insulin sensitivity might be reduced at dawn because of the prolonged fasting state.

Insulin action was found to be impaired at dawn as compared to the early night hours both at "low" $(\approx 25$ $\mathrm{mU} / 1)$ and "high" ( $\approx 80 \mathrm{mU} / 1)$ plasma free insulin concentration of the present experiment, suggesting that decreased insulin sensitivity at that time of the day is a generalised, rather than a selective phenomenon. In the clinical condition of insulin-treated diabetic subjects, plasma free insulin concentrations are generally lower than $25 \mathrm{mU} / \mathrm{l}$ in the pre-breakfast state $[26,27]$ and greater than $35 \mathrm{mU} / \mathrm{l}$ in the post-breakfast state $[42,43]$. Thus, the results of the clamp experiments of the present studies at $\approx 25 \mathrm{mU} / 1$ plasma free insulin concentration in which only glucose production was exaggerated in the early morning hours, demonstrate that the dawn phenomenon causes prebreakfast hyperglycaemia $[1,13,19,22,27,44]$ primarily by accelerating glucose production by the liver, and not by decreasing glucose utilisation by peripheral tissues. Since, however, in the clamp experiments of the present studies at $\approx 80 \mathrm{mU} / \mathrm{l}$ plasma free insulin concentration, peripheral glucose utilisation was reduced in the early morning hours, it is likely that reduced utilisation of glucose by insulin-dependent tissues, primarily muscle [45], in addition to overproduction of glucose by the liver, contributes as well to the post-breakfast hyperglycaemia caused by the dawn phenomenon $[42,43]$.

In the present studies, suppression of nocturnal spikes of growth hormone secretion resulted in a virtually full reversal of hepatic insulin resistance at dawn, whereas replacement of nocturnal spikes of growth hormone reproduced the decrease in hepatic insulin sensitivity observed in the studies in which spontaneous growth hormone secretion occurred. Although in the present studies the role of growth hormone in inducing peripheral insulin resistance at dawn was not examined, it is likely that nocturnal spikes of growth hormone were responsible for extrahepatic insulin resistance at dawn as well. In fact, previous studies have shown that physiological increases in growth hormone can at the same time augment hepatic glucose output and suppress insulin-mediated glucose utilisation after a time lag of 3-4 $\mathrm{h}$ [46-48]. Thus, the present studies demonstrate that nocturnal surges of growth hormone secretion account for virtually all of the decrease in insulin sensitivity observed at dawn in Type 1 diabetes.

Previous studies by Campbell et al. [15], Davidson et al. [16] and Atiea et al. [17] have indicated that nocturnal secretion of growth hormone is responsible for the dawn phenomenon. However, in the studies of Davidson et al. [16], plasma insulin concentrations were not reported at all. In the studies of Atiea et al. [17], the diabetic subjects were deliberately insufficiently insulin-treated overnight. Finally, in the series of studies of Campbell et al. [11, 13, $15,49]$ the diabetic subjects were given a fixed rate of insulin infusion $\left(0.15 \mathrm{mU} \cdot \mathrm{kg}^{-1} \cdot \mathrm{min}^{-1}\right)$ which resulted in a decrease in plasma free insulin concentration by $\approx 30 \%$ at dawn as compared to the early night hours as a result of the so-called Biostator artifact $[13,21]$. Thus, the extent to which nocturnal surges of growth hormone contributed specifically to fasting hyperglycaemia independently of insulin deficiency could not be determined in previous studies [15-17], in which overnight insulin deficiency was a confounding variable. In contrast, in the present studies, waning of insulin was prevented by infusing the diabetic subjects insulin at a variable rate according to the individual subjects' minute-to-minute insulin requirements [3], by means of a Harvard pump which does not cause inactivation of the infused insulin $[13,21]$. Under these experimental conditions, the decrease in insulin sensitivity in the early morning hours, namely the dawn phenomenon [8] could be attributed specifically to the nocturnal surges in growth hormone. However, because of the design of the present experiments (euglycaemic clamp) the contribution of growth hormone-induced insulin resistance to fasting hyperglycaemia could not be assessed in these studies and any direct comparison with previous studies [15-17] using a different experimental design (insulin infusion at a fixed rate) is not possible.

Finally, the results of the present studies reaffirm that insulin clearance does not change overnight in Type 1 diabetes mellitus, and does not contribute to the dawn phenomenon, as previously reported $[3,13,14]$. Notably, in the present experiments, suppression or replacement of nocturnal spikes of growth hormone secretion did not affect insulin clearance. Thus, the present study indicates that nocturnal secretion of growth hormone contributes 
to the dawn phenomenon directly, i. e. by decreasing sensitivity to insulin, rather than indirectly by increasing insulin clearance, as recently proposed $[17,50]$.

Acknowledgments. These studies were supported by the Italian National Research Council (C.N.R. grant 88.00444.04). The editorial assistance of Ms. P.Boyce, and the support from the Holiday Inn Menzies, Sydney, Australia, are gratefully acknowledged.

\section{References}

1. Deckert T, Lørup B (1976) Regulation of brittle diabetics by a pre-planned insulin infusion programme. Diabetologia 12: 573579

2. Clarke WL, Haymond MW, Santiago JV (1980) Overnight basal requirements in fasting insulin-dependent diabetics. Diabetes 29: $78-80$

3. De Feo P, Perriello G, Ventura MM, Calcinaro F, Basta G, Lolli C, Cruciani C, Dell'Olio A, Santeusanio F, Brunetti P, Bolli GB (1986) Studies on overnight insulin requirements and metabolic clearance rate of insulin in normal and diabetic man: relevance to the pathogenesis of the dawn phenomenon. Diabetologia 29: $475-480$

4. Bolli GB, Gerich JE (1984) The "Dawn Phenomenon" - a common occurrence in both non-insulin-dependent and insulin-dependent diabetes mellitus. $N$ Engl J Med 310: 746-750

5. Dimitriadis G, Vlachonikolis IG, Hatziagellaki $\mathrm{E}$, Linos A, Kodonouri O, Alexopoulos E, Raptis S (1988) The dawn phenomenon in patients with type II diabetes mellitus. Diab Nutr Metab 1:37-41

6. Schmidt MI, Lin QX, Gwynne JT, Jacob S (1984) Fasting early morning rise in peripheral insulin: evidence of the dawn phenomenon in nondiabetics. Diabetes Care 7: 32-35

7. Bolli GB, De Feo P, De Cosmo S, Perriello G, Ventura M, Calcinaro F, Lolli C, Campbell P, Brunetti P, Gerich JE (1984) Demonstration of a dawn phenomenon in normal human volunteers. Diabetes 33:1150-1153

8. Bolli GB (1988) The dawn phenomenon: its origin and contribution to early morning hyperglycaemia in diabetes mellitus. Diabete \& Metabolisme 14:675-686

9. Kerner W, Navaascués I, Torres AA, Pfeiffer EF (1984) Studies on the pathogenesis of the dawn phenomenon in insulin-dependent diabetic patients. Metabolism 33: 458-464

10. Skor DA, White NH, Thomas L, Santiago JV (1984) Relative roles of insulin clearance and insulin sensitivity in the prebreakfast increase in insulin requirements in insulin-dependent diabetic patients. Diabetes 33: 60-63

11. Campbell PJ, Bolli GB, Cryer PE, Gerich JE (1985) Sequence of events during development of the dawn phenomenon in insulindependent diabetes mellitus. Metabolism 34: 1100-1104

12. Dux S, White NH, Skor DA, Santiago JV (1985) Insulin clearance contributes to the variability of nocturnal insulin requirement in insulin-dependent diabetes mellitus. Diabetes 34:1260-1265

13. Campbell P, Gerich JE (1986) Occurrence of the dawn phenomenon without a change in insulin clearance in patients with insulindependent diabetes mellitus. Diabetes 35: 749-752

14. Widmer A, Keller U, Pasquel M, Berger W (1988) Alterations in insulin clearance and hepatic blood flow during the night do not contribute to the "dawn phenomenon" in Type 1 diabetes. Horm Res 29: 197-201

15. Campbell PJ, Bolli GB, Cryer PE, Gerich JE (1985) Pathogenesis of the dawn phenomenon in patients with insulin-dependent diabetes mellitus: accelerated glucose production and impaired glucose utilization due to nocturnal surges in growth hormone secretion. N Engl J Med 312: 1473-1479

16. Davidson MB, Harris MD, Ziel FH, Rosenberg CS (1988) Suppression of sleep-induced growth hormone secretion by anticholinergic agents abolishes dawn phenomenon. Diabetes 37: 166-171
17. Atiea JA, Creagh F, Page M, Owens DR, Scanlon MF, Peters JR (1989) Early morning hyperglycaemia in insulin-dependent diabetes: acute and sustained effects of cholinergic blockade. J Clin Endocrinol Metab 69: 390-395

18. Mauras N, Rogol AD, Clarke WL (1986) Failure to detect the dawn phenomenon in nondiabetic subjects with markedly different patterns of nocturnal growth hormone secretion. J Clin Endocrinol Metab 62: 975-979

19. Beaufrère B, Beylot M, Metz C, Ruitton A, François R, Riou JP, Mornex R (1988) Dawn phenomenon in Type 1 (insulin-dependent) diabetic adolescents: influence of the nocturnal growth hormone secretion. Diabetologia 31: 607-611

20. Skor DA, White NH, Thomas L, Santiago JV (1985) Influence of growth hormone on overnight insulin requirements in insulindependent diabetics. Diabetes 34: 135-139

21. Brennan JR, Gebhart SSP, Blackard WG (1985) Pump-induced insulin aggregation: a problem with the Biostator. Diabetes 34: 353-359

22. Koivisto VA, Yki-Järvinen H, Helve E, Karonen SL, Pelkonen R (1986) Pathogenesis and prevention of the dawn phenomenon in diabetic patients treated with CSII. Diabetes 35:78-82

23. Faber O, Binder C (1977) C-peptide response to glucagon: a test for the residual B-cell function in diabetes mellitus. Diabetes 26 : 605-610

24. Naka K, Yamazaki K, Yamamoto H (1981) Development of glycosylated hemoglobin A1c Auto-analyzer. J Clin Lab Automation 6: 22-24

25. Bolli GB, Dimitriadis GD, Pehling GB, Baker BA, Haymond NW, Cryer PE, Gerich JE (1984) Abnormal glucose counterregulation after subcutaneous insulin in insulin-dependent diabetes mellitus. N Engl J Med 310: 1706-1711

26. Francis AJ, Home PD, Hanning I, Alberti KGMM, Turnbridge WMG (1983) Intermediate acting insulin given at bedtime: effect on blood glucose concentrations before and after breakfast. $\mathrm{Br}$ Med J 286: 1173-1176

27. Bending JJ, Pickup JC, Collins ACG, Keen H (1985) Rarity of a marked "dawn phenomenon" in diabetic subjects treated by continuous insulin infusion. Diabetes Care 8: 28-33

28. De Feo P, Perriello G, Ventura MM, Brunetti P, Santeusanio F, Gerich J, Bolli GB (1987) The pancreatic-adrenocortical-pituitary clamp technique for study of counterregulation in humans. Am J Physiol 252: E565-E570

29. McGuire E, Helderman J, Tobin R, Andres R, Berman M (1976) Effects of arterial versus venous sampling on analysis of glucose kinetics in man. J Appl Physiol 41:565-573

30. Rizza RA, Cryer PE, Gerich JE (1979) Role of glucagon, catecholamines, and growth hormone in human glucose counterregulation: effects of somatostatin and combined $\alpha$ - and $\beta$-adrenergic blockade on plasma glucose recovery and glucose flux rates after insulin-induced hypoglycaemia. J Clin Invest 64: 62-71

31. Faber O, Binder C, Markussen J, Heding L, Naithand V, Kuzuya H, Blix PM, Horwitz DL, Rubenstein A (1978) Characterization of seven C-peptide antisera. Diabetes 27 [Suppl.1]:170-177

32. Faloona G, Unger RH (1974) Glucagon. In: Jaffè B, Berman H (eds) Methods of hormone radioimmunoassay. Academic Press, New York, pp 317-330

33. Peake G (1974) Growth hormone. In: Jaffè B and Berman H (eds) Methods of hormone radioimmunoassay. Academic Press, New York, pp 103-121

34. Kuzuya H, Blix PM, Horwitz DL, Steiner DF, Rubenstein AH (1977) Determination of free and total insulin and C-peptide in insulin-treated diabetics. Diabetes 26: 22-29

35. Perriello G, Torlone E, Di Santo S, Fanelli C, De Feo P, Santeusanio F, Brunetti P, Bolli GB (1988) Effect of storage temperature of insulin mixtures injected subcutaneously in subjects with Type 1 (insulin-dependent) diabetes mellitus. Diabetologia 31: $811-815$

36. De Bodo R, Steele R, Altzuler N, Dunn A, Bishop J (1963) On the hormonal regulation of carbohydrate metabolism: studies with C 14 glucose. Rec Prog Horm Res 19: 445-448 
37. Miles J, Haymond M, Gerich JE (1982) Effects of free fatty acids, insulin, glucagon, and adrenaline on ketone body production in humans. In: Metabolic acidosis, Ciba Foundation Symposium 87. Pitman Books, London, pp 192-213

38. Cobelli C, Mari A, Ferrannini E (1987) The non-steady state problem: error analysis of Steele's model and new developments for glucose kinetics. Am J Physiol 252: E679-E689

39. De Fronzo R, Ferrannini E, Hendler R, Felig P, Wahren J (1983) Regulation of splanchnic and peripheral glucose uptake by insulin and hyperglycemia in man. Diabetes 32: 32-45

40. Zar J (1984) Statistical analysis. Prentice Hall, Englewood Cliffs

41. Anderson BN (1973) The effect of fasting on insulin secretion and the Staub-Traugott phenomenon in pigs. J Endocrinol 58: $613-625$

42. Rizza R, Gerich J, Haymond M, Westland R, Hall L, Clemens A, Service J (1980) Control of blood sugar in insulin-dependent diabetes: comparison of an artificial endocrine pancreas, continuous subcutaneous insulin infusion and intensified conventional insulin therapy. N Engl J Med 303: 1313-1318

43. Calabrese G, Bueti A, Santeusanio F, Giombolini A, Zega G, Angeletti G, Cartechini MG, Brunetti P (1982) Continuous subcutaneous insulin infusion in insulin-dependent diabetic patients: a comparison with conventional optimized treatment in a long-term study. Diabetes Care 5: 457-465

44. Perriello G, De Feo P, Torlone E, Calcinaro F, Ventura MM, Basta G, Santeusanio F, Brunetti P, Gerich JE, Bolli GB (1988) Asymptomatic nocturnal hypoglycemia: a cause for deterioration of glycemic control in diabetes mellitus. N Engl J Med 319: 1233-1239

45. De Fronzo RA (1988) The triumvirate: B-cell, muscle, liver. A collusion responsible for NIDDM. Diabetes 37: 667-687
46. McGorman L, Rizza R, Gerich J (1981) Physiological concentrations of growth hormone exert insulin-like and insulin antagonist effects on both hepatic and extra-hepatic tissues in man. $\mathbf{J}$ Clin Endocrinol Metab 53: 556-559

47. Rizza R, Mandarino L, Gerich J (1982) Effects of growth hormone on insulin action in man: mechanisms of insulin resistance, impaired suppression of glucose production and impaired stimulation of glucose utilization. Diabetes 31: 663-669

48. De Feo P, Perriello G, Torlone E, Ventura MM, Santeusanio F, Brunetti P, Gerich JE, Bolli GB (1989) Demonstration of a role for growth hormone in glucose counterregulation. Am J Physiol 256: E835-E843

49. Campbell PJ, Bolli GB, Gerich JE (1988) Prevention of the dawn phenomenon (early morning hyperglycaemia) in insulin-dependent diabetes mellitus by bedtime intranasal insulin administration of a long-acting somatostatin analogue. Metabolism 37: 34-37

50. BoylePJ, Avogaro A, SmithL, Shah LD, Bier DM, Cryer PE, Santiago JU (1989) Absence of the dawn phenomenon and abnormal lipolysis in GH deficient IDDMs. Diabetes 38 [Suppl 2]: 3 A

Received: 9 February 1989;

and in final revised form: 14 September 1989

Prof. G.B.Bolli

Istituto Patologia Medica

dell'Università

Via E. Dal Pozzo

I-06100 Perugia

Italy 